\title{
Electrospinning of alumina nanofibers using different precursors
}

\author{
P. K. Panda $\cdot$ S. Ramakrishna
}

Received: 28 November 2006/ Accepted: 5 February 2007/Published online: 24 February 2007

(C) Springer Science+Business Media, LLC 2007

Electrospinning technique is becoming increasingly popular for the preparation of nanofibers [1-5]. The process involves the application of a strong electrostatic field to a capillary connected with a reservoir containing a polymer solution or melt. Under the influence of the electrostatic field, a pendant droplet of the polymer solution at the capillary tip is deformed into a conical shape (Taylor cone). If the voltage surpasses a threshold value, electrostatic forces overcome the surface tension, and a fine charged jet is ejected. The jet moves towards a ground plate, which acts as a counter electrode. The solvent begins to evaporate immediately after the jet is formed. The result is the deposition of nanofibers on a substrate located above the counter electrode. Initially, this technique was used for the preparation of polymer nanofibers [6-9]. In recent years; this technique has been used for the preparation of metal oxide/ceramic nanofibers such as silica, zirconia, titania, nickel oxide, barium titanate, lead zirconate titanate and other oxide materials [1030]. The nanofibers formed could be aligned (parallel and cross patterns) when an insulated cylinder attached to the axel of a DC motor is used as the substrate [31]. Xia et al. [32] prepared polymeric and ceramic nanofibers as axially aligned arrays by the use of a collector consisting of two pieces of electrically conductive substrate separated by a gap. Katta et al. used copper

P. K. Panda $(\square)$

Materials Science Division, National Aerospace

Laboratories, Bangalore 560 017, India

e-mail: pkpanda@css.nal.res.in

S. Ramakrishna

Department of Mechanical Engineering, University

of Singapore, Singapore, Singapore wires spaced evenly in the form of a circular drum as a collector of the electro spun nanofibers [33].

Alumina is one of the most widely used ceramic material finds applications as structural component for high temperature applications, heat engine and aerospace applications, as electronic substrates etc [34-35]. It is also used for adsorption / chemisorptions of heavy toxic metal ions such as arsenic or arsenate. The chemisorptions depends on exposed surface area, therefore, nanofibers with high surface area produced by electrospinning might be ideal for this application.

In this study, attempts have been made to prepare alumina nanofibers by electrospinning technique by studying the effect of different chemical precursors and other processing parameters on morphology of nanofibers.

Polyvinyl Alcohol (PVA) $\left(\mathrm{M}_{\mathrm{n}}, 80,000-1,23,000\right)$ and Poly Ethylene Oxide (PEO) $\left(\mathrm{M}_{\mathrm{n}}, 9,00,000\right)$ supplied by $\mathrm{M} / \mathrm{s}$ Aldrich were used as the polymer precursors. Analytical grade aluminum nitrate nano hydrate, $\mathrm{Al}\left(\mathrm{NO}_{3}\right)_{3} \cdot 9 \mathrm{H}_{2} \mathrm{O}$ and aluminum acetate supplied by $\mathrm{M} / \mathrm{s}$. Aldrich were used as the source of alumina precursors. Based on initial experiments, PVA solution $(10 \%$ by wt.) and PEO solution (5\% by wt.) were selected as the optimum polymer precursor concentration. These solutions were prepared in hot water (for PVA) and in cold water (for PEO) while stirring well with a magnetic stirrer. Similarly, $20 \%$ aluminium nitrate or aluminium acetate solutions were prepared separately. The composite solutions of PVA or PEO and aluminium nitrate or aluminium acetate were prepared by mixing appropriate amounts with a magnetic stirrer. The homogeneous solutions thus prepared were used for electrospinning. The prepared viscous solutions of PVA/aluminum nitrate, PVA/aluminum acetate and 


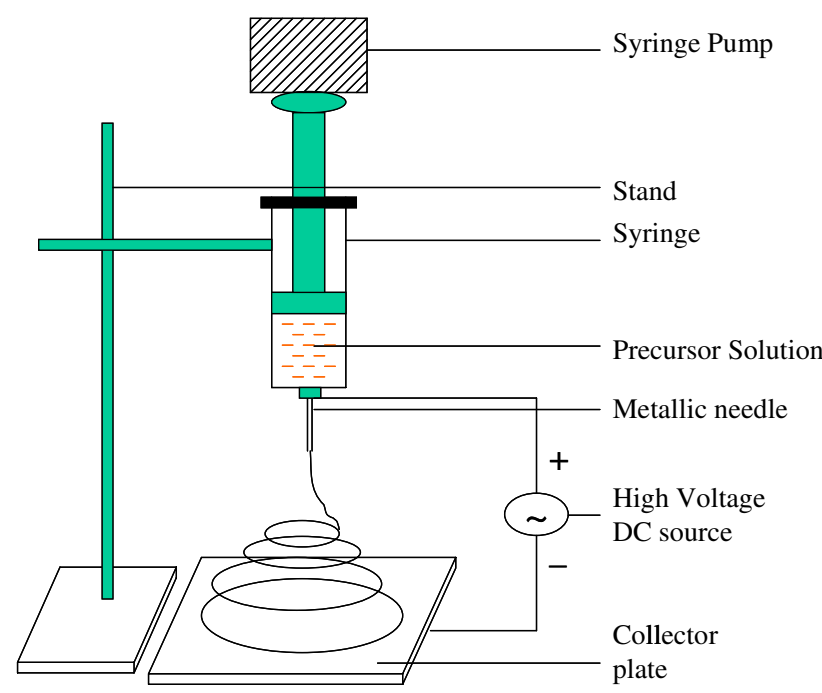

Fig. 1 Schematic diagram of electrospinning set up

$\mathrm{PEO} /$ aluminum nitrate were subjected to electrospinning by taking a small quantity of the solution in a syringe and connecting it to the positive terminal of the high voltage source. A grounded flat metallic stand covered with aluminum foil served as the counter electrode. The experiments were carried out by maintaining a distance of $10 \mathrm{~cm}$ between the tip to collector distance (TCD). A schematic drawing of the electrospinning set up is presented in Fig. 1. The solution flow rate was maintained $1.3 \mathrm{ml} / \mathrm{l}$ and the humidity of the chamber was maintained in the range of $50-60 \%$. The voltage was gradually increased till the liquid came out

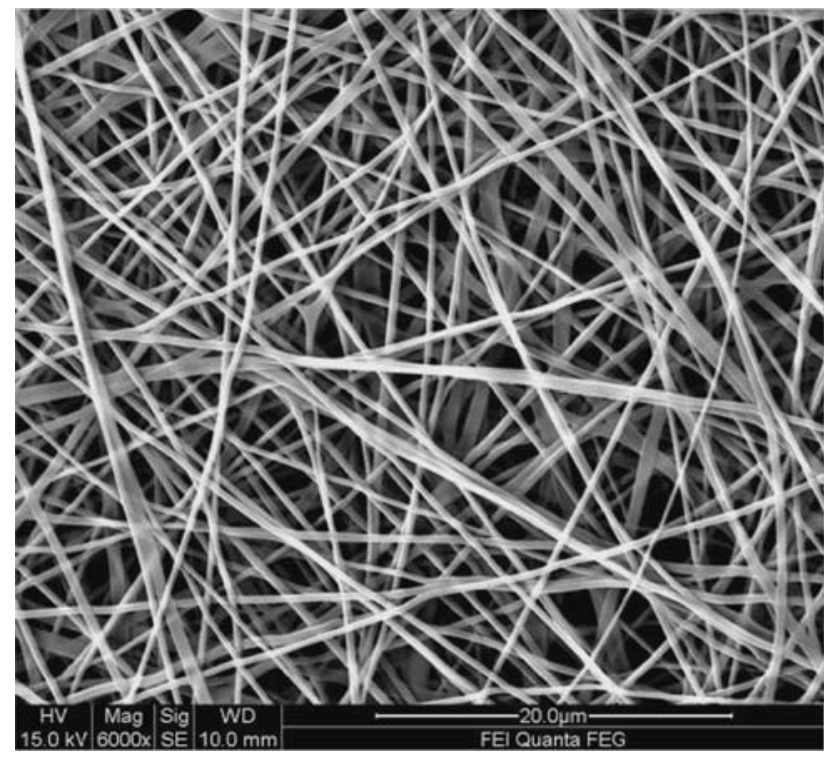

Fig. 2 SEM picture of PVA nanofibers

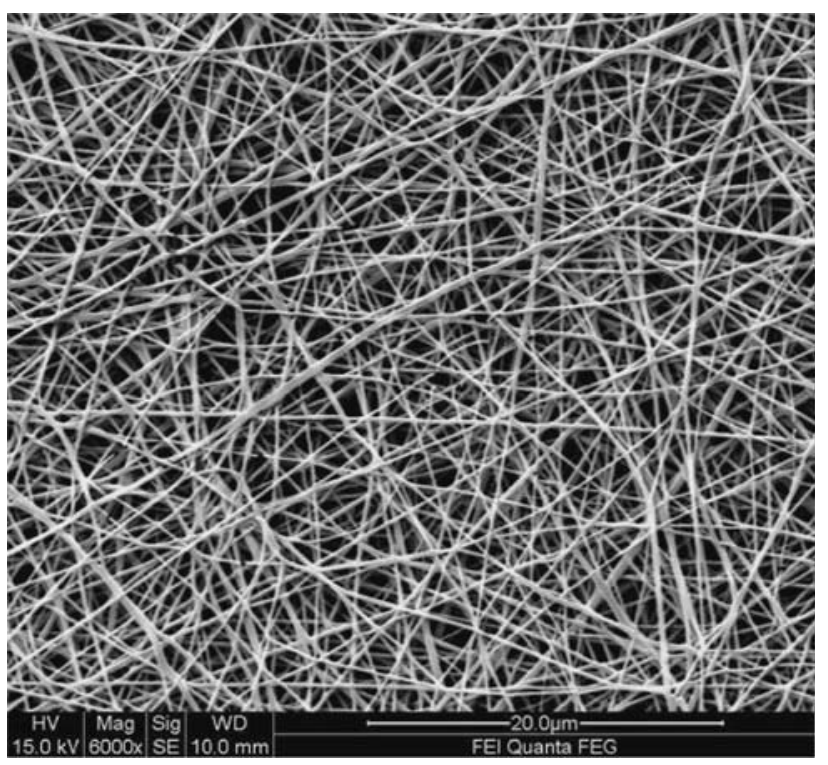

Fig. 3 SEM picture of PEO nanofibers

through the needle and split into web of fibers collected on the aluminum foil. The voltage was maintained in the range of $11-13 \mathrm{kV}$ for pure PEO and PVA solutions. SEM pictures of the PVA and PEO fibers are presented in the Figs. (2-3). Similarly, the electrospinning of composite solutions were carried out at a voltage of $17-19 \mathrm{kV}$ and their SEM pictures are presented in Figs. (4-6). The solution preparation methodology and electrospinning conditions are summarized in Table 1

In general, the electrospinning of both PVA and PEO was possible and was smooth in case of aluminum

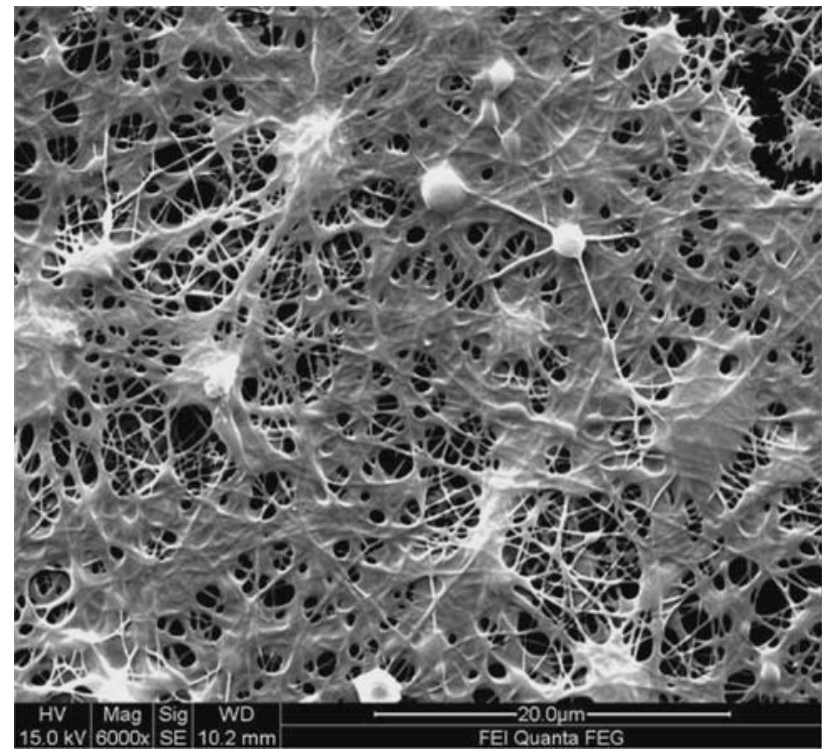

Fig. 4 SEM picture of PVA/aluminum nitrate nanofibers 


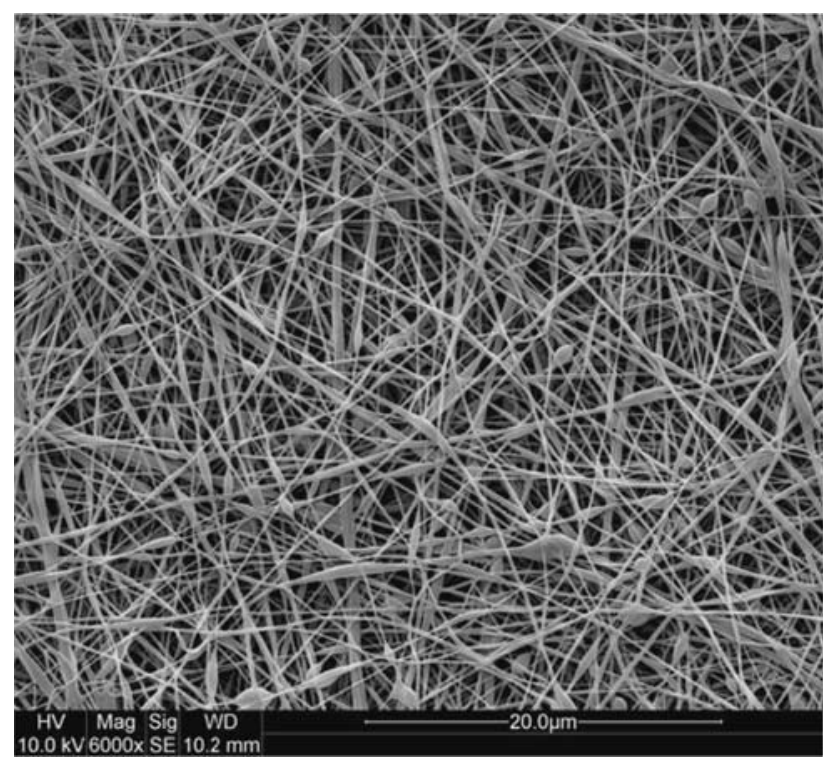

Fig. 5 SEM picture of PVA/aluminum acetate nanofibers

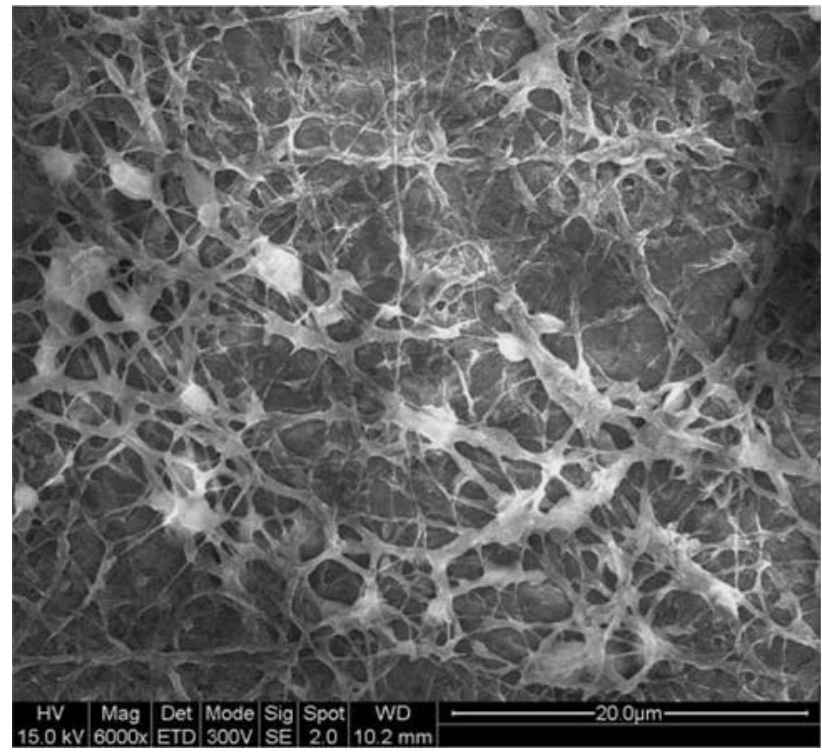

Fig. 6 SEM picture of PEO/aluminum nitrate nanofibers

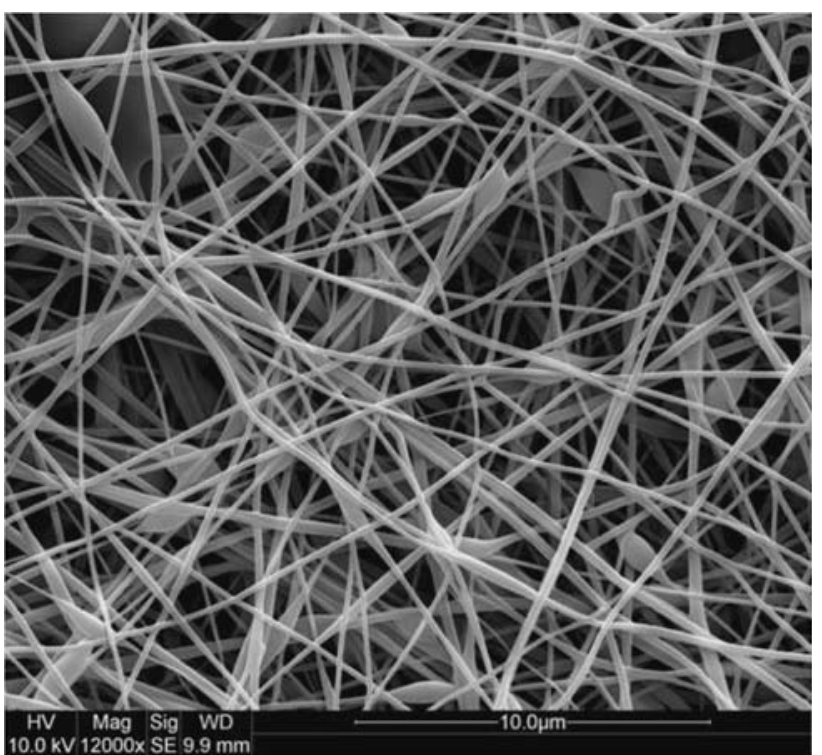

Fig. 7 SEM picture of PVA/Al acetate nanofibers at $10 \%$ solid loading

acetate precursor. In case of aluminum nitrate precursor, the resulted nanofibers are highly hygroscopic due to presence of nitrate anions and their collection was extreme difficult due to strong repulsion perhaps due to concentration of similar charges leading to the fibers either to remain in vertical position on the collector or were simply flying making it difficult for their collection. Therefore, the PVA/aluminium acetate solutions were ideal for electrospinning

In order to increase the alumina content in the fibers, three compositions of salt to polymer ratio i.e. $10 \%, 50 \%$ and $100 \%$ were electrospun. It was observed that the electrospinning was very smooth for $10 \%$ as well as $50 \%$ solid loading. Typical morphology of nanofibers obtained by different solid loading is presented in Figs. (7-8). The presence of beads were observed in case of low solid loading (10\%) compared, while the same were absent in higher solid loading $(50 \%)$.

The prepared nanofibers were heat treated at $900{ }^{\circ} \mathrm{C}$ and $1300{ }^{\circ} \mathrm{C}$ in order to remove the organics to

Table 1 Solution preparation methodology and electrospinning conditions

\begin{tabular}{|c|c|c|}
\hline Chemical Precursors & Preparation of Solution & Electro spinning Conditions \\
\hline $\begin{array}{l}\text { PolyVinyl Alcohol } \\
\text { (PVA) (Mn, } \\
80,000-1,23,000)\end{array}$ & $\begin{array}{l}10 \% \text { PVA solution was prepared in hot water by heating } \\
\text { at } 80{ }^{\circ} \mathrm{C} / 12 \mathrm{~h} \text { with magnetic stirring. Required amount } \\
\text { of salt was added to PVA solution and were mixed for } \\
5 \mathrm{~h} \text {. }\end{array}$ & $\begin{array}{l}\text { Nozzle Dia. (internal) }-8.5 \mathrm{~mm} \text { Tip to Collector } \\
\text { Distance (TCD) }-10 \mathrm{~mm} \text { Voltage- }-11-13 \mathrm{kV} \text { (for } \\
\text { pure PVA and PVO) Voltage- }-19 \mathrm{kV} \text { (for } \\
\text { polymer and salt solution) Humidity-50-60\% }\end{array}$ \\
\hline $\begin{array}{l}\text { Poly Ethylene Oxide } \\
\quad(\mathrm{PEO}) \\
\quad(\mathrm{Mn},-9,00,000)\end{array}$ & $\begin{array}{l}5 \% \text { PEO solution was prepared in cold water by stirring } \\
\text { well in a magnetic stirrer. Required amount of salt was } \\
\text { added to PEO solution and were mixed for } 5 \mathrm{~h} \text {. }\end{array}$ & \\
\hline
\end{tabular}




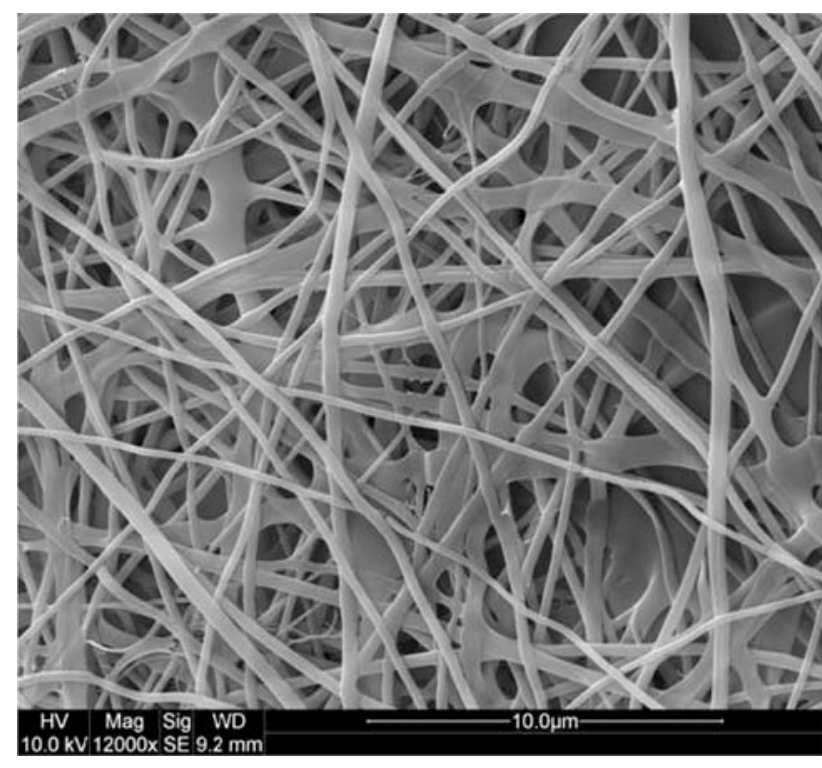

Fig. 8 SEM picture of PVA/Al acetate nanofibers at 50\% solid loading

generate pure alumina nanofibers. They are presented in the Figs. (9-10). The XRD analysis (Fig. 11) of the calcined product at $1300{ }^{\circ} \mathrm{C}$ confirms the presence of pure alpha alumina phase. From Fig. 10, it is observed that the nanofibers heated at $900{ }^{\circ} \mathrm{C}$ are characterized by beaded structure due to loss of organics leaving the porous unsintered alumina phase. However, at high temperature, the diameters of the fibers are further reduced due to sintering. The diameters of the fibers are in the range of $20-500 \mathrm{~nm}$.

To summarize, alumina nanofibers were successfully prepared by electrospinning technique using different

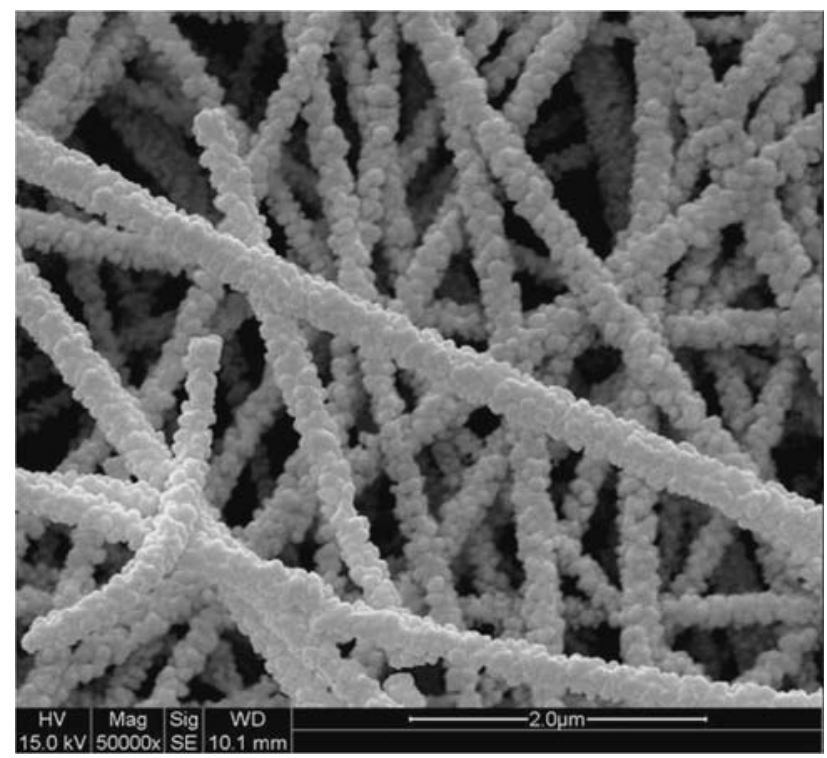

Fig. 9 SEM picture of Alumina nanofibers heat treated at $900{ }^{\circ} \mathrm{C}$

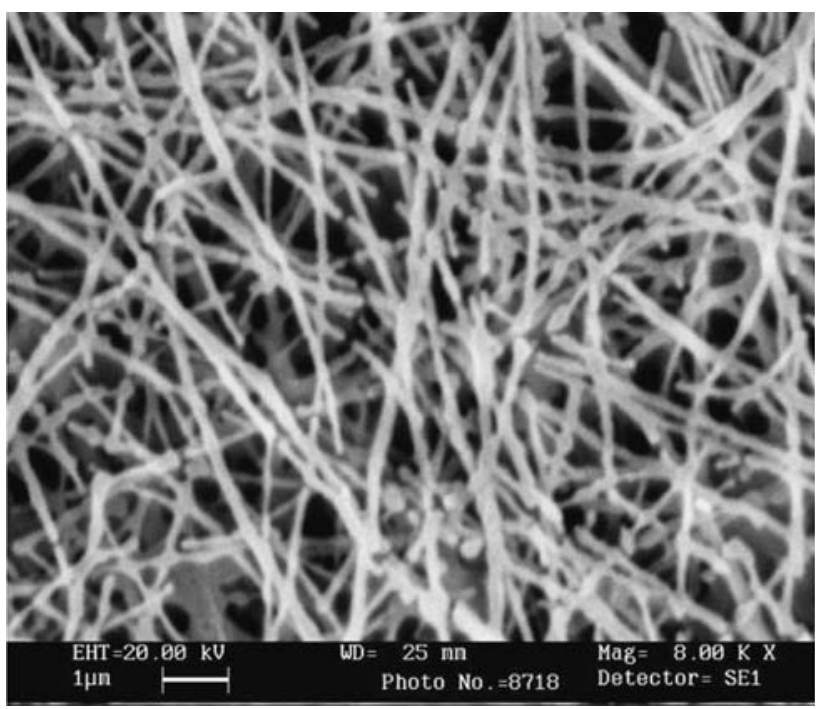

Fig. 10 SEM picture of Alumina nanofibers heat treated at $1,300{ }^{\circ} \mathrm{C}$

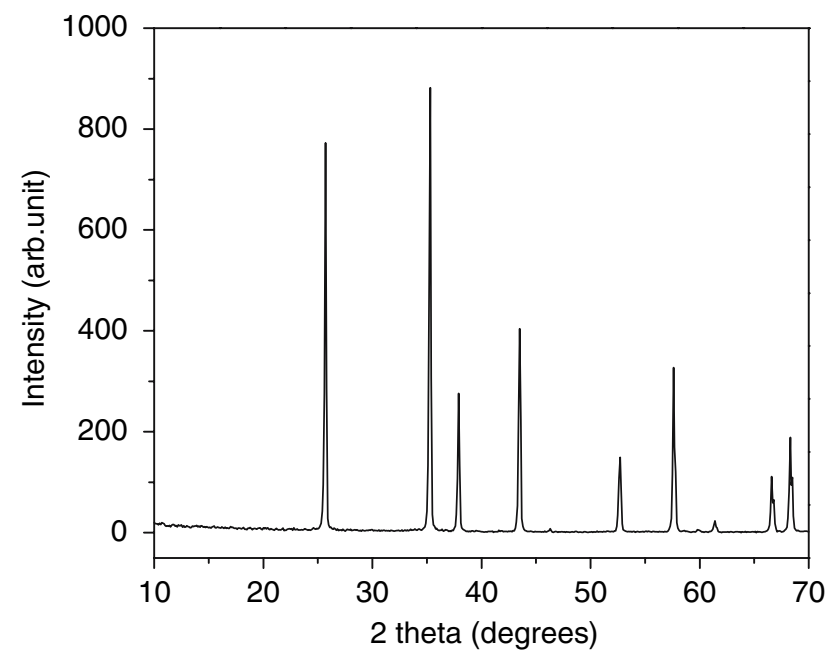

Fig. $11 \mathrm{XRD}$ of Alumina nanofibers heat treated at $1,300{ }^{\circ} \mathrm{C}$

precursors from a combination of PVA and PEO as polymer precursor, aluminium acetate and aluminium nitrate as alumina precursor. It was possible to electrospun a solution containing upto $50 \% \mathrm{Al}$ precursor.

Acknowledgements The authors would like to thank Dr Kazu for his help during the study. One of the authors, Dr PK Panda would like to thank CSIR, New Delhi for awarding "Raman Research Fellowship" to carry out this work at NUS, Singapore.

\section{References}

1. Reneker DH, Chun I (1996) Nanotechnology 7:216

2. Tan S-H, Inai R, Kotaki M, Ramakrishna S (2005) Polymer 46:6128

3. Li DAN, Xia Y (2004) Adv Mater 16:1151 
4. Doshi J, Reneker DH (1995) J Electrostat 35:51

5. Deitzel JM, Kleinmeyer J, Harris D, Beck Tan NC (2001) Polymer 42:261

6. Yarin AL, Koombhongse S, Reneker DH (2001) J Appl Phys 90:4836

7. Jayaraman K, Kotaki M, Zhang Y, Mo X, Ramakrishna S (2004) J Nanosci Nanotech 4:52

8. Frenot A, Chronakis IS (2003) Curr Opin Colloid Interface Sci 8:64

9. Huang ZM, Zhang Y-Z, Kotaki M, Ramakrishna S (2003) Composites Sci Tech 63:2223

10. Li D, Herricks T, Xia YN (2003) Appl Phys Lett 83:4586

11. Wang Y, Santiago-Aviles JJ (2004) Nanotechnology 15:32

12. Dharmaraj N, Park HC, Lee BM, Viswanathamurthi P, Kim HY, Lee DR (2004) Inorg Chem Commun 7:431

13. Dharmaraj N, Park HC, Kim CK, Kim HY, Lee DR (2004) Mater Chem Phys 87:5

14. Dai HQ, Gong J, Kim H, Lee D (2002) Nanotechnology 13:674

15. Yang XG, Shao CL, Liu YC, Mu RX, Guan HY (2005) Thin Solid Films 478:228

16. Shao CL, Guan HY, Liu YC, Gong J, Yu N, Yang XH (2004) J Cryst Growth 267:380

17. Viswanathamurthi P, Bhattarai N, Kim HY, Khil MS, Lee DR, Suh EK (2004) J Chem Phys 121:441

18. Shao CL, Guan HY, Liu YC, Li XL, Yang XH (2004) J Solid State Chem 177:2628

19. Guan HY, Shao CL, Wen SB, Chen B, Gong J, Yang XH (2003) Mater Chem Phys 82:1002
20. Viswanathamurthi P, Bhattarai N, Kim HY, Lee DR, Kim SR, Morris MA (2003) Chem Phys Lett 374:79

21. Madhugiri S, Sun B, Smirniotis PG, Ferraris JP, Balkus KJ (2004) Micropor Mesopor Mater 69:77

22. Shao CL, Yang XH, Guan HY, Liu YC, Gong H (2004) Inorg Chem Commun 7:625

23. Yuh J, Nino JC, Sigmund W (2005) Mater Lett 59:3645

24. Choi SS, Lee SG, Im SS, Kim SH, Joo YL (2003) J Mater Sci Lett 22:891

25. Wang Y, Furlan R, Ramos I, Santiago-Aviles JJ (2004) Appl Phys A-Mater 78:1043

26. Dharamraj N, Kim CH, Kim HY (in press) Mater Lett

27. Ding B, Kim H, Kim C, Khil M, Park S (2003) Nanotechnology 14:532

28. Li D, Xia Y (2003) Nano Letters 4:555

29. Zhang M, Wang XD, Salvado IMM, Vilarinho PM, Li WC (2005) Ceram Int 31:281

30. Guan H, Shao C, Liu Y, Yu N, Yang X (2004) Solid State Commun 131:107

31. Sundaray B, Subramanian V, Natarajan TS (2004) Appl Phys Lett 84:1222

32. Li D, Wang Y, Xia Y (2003) Nano Lett 3:1167

33. Katta P, Alessandro M, Ramsier RD, Chase GG (2004) Nano Lett 4:2215

34. Gitzen WH (1970) Alumina as a ceramic material. The American Ceramic Society, Coloumbus, Ohio, p 43

35. Richards G (1981) Trans \& J Brit Cer Soc 80:120 